\title{
Evaluasi Psikometri Cognitive Emotion Regulation Questionnaire: Versi Indonesia
}

\section{(Psychometric Evaluation Cognitive Emotion Regulation Questionnaire: Indonesian Version)}

\author{
ANDI TENRI FARADIBA ${ }^{1}$, PUTI FEBRAYOSI ${ }^{2}$ \\ Pusat Pengukuran Psikologi Fakultas Psikologi, Universitas Pancasila \\ E-mail: ${ }^{1}$ atenri.frd@ gmail.com; ${ }^{2}$ putifeb0602@gmail.com
}

\begin{abstract}
Abstrak: Cognitive emotion regulation adalah konsep regulasi emosi yang berfokus pada proses evaluasi dan modifikasi emosi dengan menggunakan strategi kognitif. Strategi yang digunakan individu dalam mengelola emosi memiliki hubungan dengan kecenderungannya mengalami kecemasan dan depresi. Penelitian sebelumnya berhasil mengembangkan alat ukur cognitive emotion regulation dalam beberapa versi, tetapi belum ada penelitian yang membuat alat ukur tersebut versi Indonesia. Penelitian ini bertujuan melakukan adaptasi alat ukur cognitive emotion regulation questionnaire dengan menggunakan mahasiswa sebagai partisipan. Alat ukur ini terdiri dari 36 item yang terbagi ke dalam 8 dimensi, yaitu self blame, other blame, acceptance, rumination, positive refocusing, refocus on planning, positive reappraisal, putting into persepctive, dan catastrophizing. Ada sebanyak 196 mahasiswa (Laki-laki=18\% dan Perempuan $=82 \%$ ) terlibat dalam penelitian ini. Teknik pengujian validitas dan reliabilitas menggunakan Rasch Model pada aplikasi winsteps. Hasilnya adalah seluruh item dinyatakan valid dengan rentang reliabilitas alpha cronbach 0,6 hingga 0,85. Oleh karena itu, alat ukur cognitive emotion regulation questionnaire versi Indonesia dinyatakan mampu mengukur regulasi emosi kognitif secara valid.
\end{abstract}

Kata kunci: Cognitive emotion regulation questionnaire, rasch model, uji validitas dan reliabilitas

Abstract: Cognitive emotion regulation emphasized evaluation and modification of emotion using cognitive strategies. Previous research showed cognitive emotion regulation strategies correlate with anxiety and depression. There were many versions of cognitive emotion regulation questionnaire. However, Indonesian version does not develop. The aim of this study was to validate Indonesian version of the Cognitive Emotion Regulation Questionnaire (CERQ). The questionnaire evaluates nine strategies of cognitive emotional regulation: Selfblame, Acceptance, Rumination, Positive refocusing, Refocus on planning, Positive reappraisal, Putting into perspective, Catastrophizing, and Other blame. A sample of $196($ men $=18 \%$; women $=82 \%)$ undergraduates completed the questionnaire. Rasch model analyses showed that all of the items are valid and have a reliability score from 0,6 to 0,85. Thus, the Indonesian version of Cognitive Emotion Regulation Questionnaire (CERQ) is valid for assessing the cognitive components of emotional regulation.

Keywords: Cognitive emotion regulation questionnaire, rasch model, psychometric evaluation 


\section{PENDAHULUAN}

Regulasi emosi adalah proses kompleks yang terjadi dalam diri individu yang memungkinkannya mengevaluasi dan memodifikasi emosi yang terjadi. Segala aktivitas yang dilakukan individu memicu emosi tertentu yang membutuhkan strategi berbeda untuk mengontrol kehidupan emosionalnya (Koole, Dillen, \& Sheppes, 2010). Penelitian terbaru secara spesifik membedakan bentuk dari regulasi emosi berupa kognitif dan perilaku (Garnefski \& Kraaij, 2007) sehingga menjadi penutup dari kekurangan pada teori regulasi emosi Lazarus dan Folkman (1984) yang masih menggabungkan antara cognitive coping strategy dan behavioral coping strategy.

Regulasi emosi secara kognitif dibedakan atas dua jenis strategi, yaitu adaptif dan non adaptif. Strategi adaptif meliputi acceptance (menerima situasi yang terjadi), positive refocusing (berpikir tentang pengalaman yang menyenangkan dibandingkan kesulitan yang dihadapi), refocus on planning (memikirkan solusi terbaik berdasarkan masalah yang dihadapi), positive reappraisal (mempertimbangkan aspek positif dari situasi yang dialami), dan putting into perspective (mengurangi fokus pada kejadian yang dialami dan memilih melihat hal lain) sedangkan strategi non-adaptif terdiri dari self blame (menyalahkan diri sendiri), other blame (menyalahkan orang lain), rumination (merefleksikan pikiran dan perasaan terkait dengan situasi yang dialami), dan catastrophizing (berpikir negatif terhadap situasi yang dialami).

Individu yang memiliki kecenderungan menggunakan strategi non-adaptif ketika mengalami situasi pemicu stres diprediksi lebih mudah mengalami simtom-simtom depresi (Kraaji, Garnefski, De Wilde, Dijkstra, Gebhardt, \& Maes, 2003) dan kecemasan (Kraaij, Garnefski, \& Van Gerwen, 2003). Lebih lanjut perempuan lebih cenderung menggunakan strategi rumination, catastrophizing, dan positive refocusing dibandingkan laki-laki (Garnefski, Teerds, Kraaij, Lagerstee, \& Van den Kommer, 2004). Penelitian mengenai strategi regulasi emosi secara kognitif masih terus menerus dikembangkan. Hal ini ditunjukkan melalui pengadaptasian alat ukur cognitive emotion regulation questionnaire versi 
Bahasa Inggris ke dalam beberapa versi seperti, French version, Dutch version, Turkish version, Chinese version, dan Spanish version. Penelitian ini bertujuan mengembangkan alat ukur cognitive emotion regulation questionnaire versi Indonesia yang valid dan reliabel.

Dalam melakukan uji validitas terdapat dua pendekatan yang berkembang yakni klasik dan modern. Pada pendekatan klasik yakni menggunakan teori tes klasik atau classical test theory (CTT) terdapat berbagai kritik diantaranya koefisien reliabilitas yang dihasilkan berdasarkan banyaknya sampel dan skala pengukuran yang tidak linear (Hambleton, 1991). Kekurangan yang terdapat pada pendekatan klasik atau CTT ini diperbaiki dengan pendekatan modern yakni teori mengenai respon butir atau item response theory. Pendekatan modern ini menggunakan parameter logistik yakni 1 parameter logistik, 2 parameter logistik dan 3 parameter logistik. Salah satu model yakni 1 parameter logistik yang dikembangan kemudian dikenal dengan model Rasch. Hal yang membedakan antara CTT dengan model Rasch ialah bagaimana memperlakukan skor atau data mentah ketika melakukan analisis. Pada CTT, tingkat kesukaran atau threshold untuk setiap item memiliki nilai yang sama sehingga untuk mendapatkan skor setiap responden, peneliti menjumlahkan item pertama hingga item terakhir. Sedangkan pada model Rasch yang diperkenalkan oleh Goerge Rasch ditahun 1960an, untuk mendapatkan atau mengestimate kemampuan setiap responden bergantung pada tingkat kesukaran atau threshold setiap item.

\section{METODE}

Responden Penelitian. Penelitian ini melibatkan 196 mahasiswa (Laki-laki= 82\% dan perempuan=18\%) dari salah satu universitas swasta di Jakarta yang memiliki rentang usia 1826 tahun (rata-rata usia=19 tahun 7 bulan). Partisipan dipilih dengan menggunakan prinsip non-probability sampling yang tidak memberikan kesempatan kepada seluruh anggota populasi untuk menjadi partisipan berupa accidental sampling.

Instrumen Penelitian. Alat ukur Cognitive Emotion Regulation Questionnaire memiliki 9 dimensi dengan total item sebanyak 36 item. 
Versi asli alat ukur ini adalah berbahasa Inggris sehingga langkah pertama yang dilakukan berupa menerjemahkan alat ukur ke dalam Bahasa Indonesia. Ada dua penerjemah dengan kualifikasi mampu berbahasa Inggris dengan lancar dan satu diantaranya adalah orang yang memiliki pengetahuan di bidang psikologi. Lalu, proses sintesis dilakukan untuk kemudian diterjemahkan kembali ke dalam Bahasa Inggris untuk memastikan maknanya sama. Langkah berikutnya adalah alat ukur diberikan kepada 2 orang ahli dengan kualifikasi pernah melakukan penelitian terkait dengan regulasi emosi. Setelah itu, seluruh item ditunjukkan kepada 10 orang mahasiswa untuk mengecek sejauhmana katakata yang digunakan dalam item kuesioner dapat dipahami. Langkah terakhir adalah mengadministrasikan alat ukur Cognitive Emotion Regulation Questionnaire kepada seluruh partisipan.

Teknik Uji Validitas dan Reliabilitas. Alat ukur diuji dengan menggunakan model Rasch menggunakan Winsteps. 
HASIL

Tabel 1. Hasil Uji Validitas

\begin{tabular}{|c|c|c|c|c|c|}
\hline \multirow{2}{*}{ Dimensi } & \multirow{2}{*}{ Item } & \multicolumn{2}{|c|}{ OUTFIT } & \multirow{2}{*}{ Corr } & \multirow{2}{*}{ Ket. } \\
\hline & & MNSQ & ZSTD & & \\
\hline \multirow[t]{4}{*}{ Self-Blame } & Item-1 & 1,30 & 2,7 & 0,53 & Valid \\
\hline & Item-10 & 0,83 & $-1,4$ & 0,78 & Valid \\
\hline & Item-19 & 0,95 & $-0,5$ & 0,68 & Valid \\
\hline & Item-28 & 0,86 & $-1,2$ & 0,74 & Valid \\
\hline \multirow[t]{4}{*}{ Acceptance } & Item-2 & 0,77 & $-2,5$ & 0,71 & Valid \\
\hline & Item-11 & 0,67 & $-3,9$ & 0,73 & Valid \\
\hline & Item-20 & 1,82 & 6,7 & 0,37 & Valid \\
\hline & Item-29 & 0,93 & $-0,7$ & 0,59 & Valid \\
\hline \multirow[t]{4}{*}{ Rumination } & Item-3 & 0,92 & $-0,8$ & 0,71 & Valid \\
\hline & Item-12 & 0,96 & $-0,4$ & 0,61 & Valid \\
\hline & Item-21 & 1,15 & 1,4 & 0,69 & Valid \\
\hline & Item-30 & 0,88 & $-1,1$ & 0,69 & Valid \\
\hline \multirow{4}{*}{$\begin{array}{l}\text { Positive } \\
\text { Refocusing }\end{array}$} & Item-4 & 1,14 & 1,3 & 0,62 & Valid \\
\hline & Item-13 & 1,07 & 0,7 & 0,66 & Valid \\
\hline & Item-22 & 0,87 & $-1,3$ & 0,71 & Valid \\
\hline & Item-31 & 0,76 & $-2,4$ & 0,77 & Valid \\
\hline \multirow{4}{*}{$\begin{array}{l}\text { Refocus On } \\
\text { Planning }\end{array}$} & Item-5 & 0,87 & $-1,2$ & 0,77 & Valid \\
\hline & Item-14 & 0,84 & $-1,4$ & 0,78 & Valid \\
\hline & Item-23 & 1,04 & 0,4 & 0,72 & Valid \\
\hline & Item-32 & 1,04 & 0,4 & 0,73 & Valid \\
\hline \multirow{4}{*}{$\begin{array}{l}\text { Positive } \\
\text { Reappraisal }\end{array}$} & Item-6 & 1,09 & 0,9 & 0,79 & Valid \\
\hline & Item-15 & 1,09 & 0,9 & 0,79 & Valid \\
\hline & Item-24 & 1,03 & 0,3 & 0,75 & Valid \\
\hline & Item-33 & 0,73 & $-2,7$ & 0,81 & Valid \\
\hline \multirow{4}{*}{$\begin{array}{l}\text { Putting Into } \\
\text { Perspective }\end{array}$} & Item-7 & 1,11 & 1,0 & 0,71 & Valid \\
\hline & Item-16 & 0,85 & $-1,4$ & 0,70 & Valid \\
\hline & Item-25 & 0,91 & $-0,8$ & 0,71 & Valid \\
\hline & Item-34 & 1,08 & 0,8 & 0,80 & Valid \\
\hline \multirow[t]{4}{*}{ Catastrophizing } & Item-8 & 1,26 & 2,1 & 0,63 & Valid \\
\hline & Item-17 & 0,85 & $-1,3$ & 0,77 & Valid \\
\hline & Item-26 & 1,04 & 0,4 & 0,72 & Valid \\
\hline & Item-35 & 0,82 & $-1,6$ & 0,82 & Valid \\
\hline \multirow[t]{4}{*}{ Blaming Others } & Item-9 & 0,91 & $-0,6$ & 0,70 & Valid \\
\hline & Item-18 & 0,78 & $-1,6$ & 0,74 & Valid \\
\hline & Item-27 & 1,48 & 3,0 & 0,76 & Valid \\
\hline & Item-36 & 0,70 & $-2,3$ & 0,77 & Valid \\
\hline
\end{tabular}


Merujuk pada Sumintono dan Widhiarso (2014) terdapat tiga kriteria yang digunakan untuk menentukan item fit atau tidak yakni (1) nilai Outfit Mean Square yakni $0.5<$ MNSQ < 1.5 (2) nilai Outfit Z-Standard (ZSTD) yakni $-2.0<$ ZSTD $<+2.0$ dan (3) nilai Point Measure Correlation yakni $0.4<\mathrm{Pt}$ Measure Corr $<0.85$. Jika setiap item memiliki dua dari tiga kriteria yang disebutkan sebelumnya, maka item tersebut dinyatakan item fit. Namun apabila item hanya memenuhi satu kriteria, maka item dinyatakan tidak fit.

Dari tabel 1 dapat dilihat bahwa seluruh item yang digunakan pada dimensi self blame, acceptance, rumination, positive refocusing, refocus on planning, positive reappraisal, putting into perspective, catastrophizing, dan blaming others dapat dinyatakan item fit karena minimal memenuhinya dua dari tiga kriteria item fit. Setelah memaparkan mengenai item fit, kemudian peneliti memaparkan nilai reliabilitas untuk setiap dimensi yang terdapat pada tabel 2 .

Tabel 2. Hasil Uji Reliabilitas

\begin{tabular}{lccc}
\hline \multirow{2}{*}{\multicolumn{1}{c}{ Dimensi }} & \multicolumn{3}{c}{ Reliabilitas } \\
\cline { 2 - 4 } & Person & Test & Item \\
\hline Self Blame & 0,61 & 0,62 & 0,99 \\
Acceptance & 0,41 & 0,85 & 0,99 \\
Rumination & 0,59 & 0,60 & 0,46 \\
Positive Refocusing & 0,68 & 0,65 & 0,40 \\
Refocus on Planning & 0,69 & 0,74 & 0,83 \\
Positive Reappraisal & 0,71 & 0,79 & 0,80 \\
Putting into & 0,66 & 0,67 & 0,89 \\
perspective & & & \\
Catastrophizing & 0,69 & 0,74 & 0,91 \\
Blaming Others & 0,63 & 0,73 & 0,64 \\
\hline
\end{tabular}

Nilai reliabilitas test menggunakan alpha Cronbach (KR-20) untuk keseluruhan dimensi berada pada rentangan 0.60 hingga 0.85 . Nilai tersebut mengukur mengenai interaksi antara responden dengan item. Berdasarkan kriteria reliabilitas yang ada pada Sumintono dan Widhiarso (2014) nilai reliabilitas test cukup baik. Hanya pada dimensi rumination nilai reliabilitas tes paling rendah diantara kesembilan dimensi yang ada pada alat ukur Cognitive Emotion Regulation Questionnaire. Selanjutnya, melihat tabel di atas informasi mengenai reliabilitas responden, terdapat empat dimensi yang nilainya di atas 0.67 yakni positive refocusing, refocus on planning, positive reappraisal dan catastrophizing. Hal ini menunjukan konsistennya responden dalam memberikan jawaban terhadap item yang dikerjakan. Sisa dimensi yakni self blame, acceptance, rumination, putting into perspective dan blaming others dimana nilai reliabilitas person lemah karena di bawah 0.67. Hal ini menunjukan bahwa responden tidak konsisten dalam memberikan jawaban pada dimensi tersebut. Informasi terakhir yakni mengenai reliabilitas item pada alat ukur Cognitive Emotion Regulation Questionnaire terdapat delapan dimensi yang nilainya di atas 0.80 . Dapat diartikan bahwa dimensi dalam alat ukur ini memiliki reliabilitas bagus. Hanya dua dimensi yang nilai reliabilitasnya di bawah 0.5 yakni dimensi rumination dan positive refocusing. 


\section{SIMPULAN}

Kesimpulan yang diperoleh dari

penelitian ini adalah sebanyak 36 item dalam 9 dimensi pada alat ukur Cognitive Emotion Regulation Questionnaire dinyatakan memiliki keterandalan untuk mengetahui sejauh mana pilihan individu dalam meregulasi emosi ketika dihadapkan pada situasi yang memicu stress dan dinyatakan memiliki reliabilitas yang baik.

\section{DISKUSI}

Tujuan dari penelitian ini adalah melakukan evaluasi psikometri berupa pengujian validitas dan reliabilitas terhadap alat ukur Cognitive Emotion Regulation Questionnaire. Sebanyak 36 item dari sembilan dimensi yang ada memiliki kesesuaian mengukur dimensi yang ada. Hal ini berdasarkan kriteria yang telah dipaparkan sebelumnya. Namun, untuk reliabilitas masing-masing dimensi, terdapat dua dimensi yang harus diperbaiki karena nilai reliabilitasnya kurang memuaskan. Hal ini dapat diartikan jika kedua dimensi tersebut ingin digunakan berulangkali maka hasilnya tidak konsisten dan dimensi tersebut ialah rumination dan positive refocusing. Rumination adalah salah satu contoh strategi regulasi emosi kognitif yang non-adaptif yang memungkinkan individu merefleksikan perasaan dan pikirannya terkait kejadian negatif yang dialami sedangkan positive refocusing merupakan strategi adaptif yang berupaya memikirkan hal menyenangkan daripada berpikir kejadian negatif yang dialami. Kedua strategi tersebut memiliki kemiripan yang menunjukkan bahwa partisipan dalam penelitian ini mengalami kesulitan berpikir positif dan lebih mudah berpikir negatif terkait hal pemicu stres yang dialami. Partisipan dalam penelitian ini adalah remaja yang lebih banyak mengalami emosi negatif dalam menjalani kehidupan terutama kehidupan akademik (Santrock, 2007). Hal ini menjadi keterbatasan dalam proses uji validitas dan reliabilitas alat ukur Cognitive Emotion Regulation Questionnaire sehingga penelitian berikutnya diharapkan dapat menguji kembali alat ukur ini dengan partisipan pada tahap perkembangan yang lainnya dan item-item pada kedua dimensi tersebut dievaluasi sehingga hasil reliabilitas meningkat. Lebih lanjut, pengujian validitas dan reliabilitas dengan menggunak teknik selain Rasch Model juga disarankan jika penelitian serupa ingin dilakukan. 


\section{DAFTAR PUSTAKA}

Garnefski, N., \& Kraaij, V. (2007). The Cognitive Emotion Regu lation Questionnaire: Psychometric features and prospective relationships with depression and anxiety in adults. European Journal of Psychological Assessment, 23, 141149.

Garnefski, N., Teerds, J., Kraaij, V., Legerstee, J., \& Van den Kommer, T. (2004). Cognitive emotion regulation strategies and depressive symptoms: Differences between males and females. Personality and Individual Differences, 36, 267 $\square 276$.

Kraaij, V., Garnefski, N., De Wilde, E. J., Dijkstra, A., Gebhardt, W., Maes, S., et al. (2003). Negative life events and depressive symptoms in late adolescence: Bonding and cognitive coping as vulnerability factors? Journal of Youth and Adolescence, 32(3), 185 $\square 193$.

Kraaij, V., Garnefski, N., \& Van Gerwen, L. (2003). Cognitive coping and anxiety symptoms among people who seek help for fear of flying. Aviation, Space, and Environmental Medicine, 74, 273 $\square 277$.

Koole, S. L., Dillen, L. F. V., Sheppes, G. (2010). The self-regulation of emotion. Dalam Handbook of self-regulation. New York ; Guilford Press

Lazarus, R. S., \& Folkman, S. (1984). Stress, appraisal and coping. New York, NY: Springer.

Ronald K. Hambleton dan Hariharan Swaminathan. (1991). Item Response
Theory; Principles and Applications. Kluwer, Nijhoff Publishing.

Sumintono, B dan Widhiarso, W. (2014). Aplikasi Model Rasch untuk Penelitian Ilmu-ilmu Sosial. Cimahi: Trim Komunikata Publishing House. 